\title{
Não preferência para alimentação e antibiose em cultivares de amendoim a Stegasta bosquella (Chambers) (Lepidoptera: Gelechiidae)
}

\section{Non-preference for feeding and antibiosis in peanut cultivars to Stegasta bosquella (Chambers) (Lepidoptera: Gelechiidae)}

\author{
Mirella Marconato Di Bello; Bruno Henrique Sardinha de Souza²; \\ Júlio César Janini²; Arlindo Leal Boiça Júnior ${ }^{3 *}$
}

\section{Resumo}

Este trabalho teve como objetivos avaliar a atratividade, não preferência para alimentação e antibiose em cultivares de amendoim de hábitos de crescimento ereto e rasteiro a Stegasta bosquella (Chambers). Avaliaram-se oito cultivares, sendo quatro de hábito de crescimento ereto (IAC Tatu, IAC 22, IAC 8112 e IAC 5) e quatro de hábito rasteiro (IAC Runner 886, IAC 147, IAC 125 e IAC 503). Foram realizados testes de não preferência para alimentação com e sem chance de escolha, utilizando-separes de discos foliares sobrepostos de 1,0 cm de diâmetro, os quais foram dispostos em placas de Petri onde foram liberadas lagartas de terceiro instar de $S$. bosquella. Avaliou-se a atratividade das lagartas em tempos pré-estabelecidos, além da massa seca consumida. No teste de antibiose, foram avaliados os parâmetros biológicos: período e viabilidade larval, de pré-pupa, pupal e total, pesos de lagartas e pupas, razão sexual e longevidade. Nenhuma das cultivares de amendoim de hábito de crescimento rasteiro apresentaram resistência do tipo não preferência para alimentação. Dentre as cultivares de hábito de crescimento ereto, IAC 5 e IAC 22 foram as menos atrativas e consumidas no teste de não preferência para alimentação com chance de escolha, e IAC 5 e IAC 8112 foram as menos atrativas no teste sem chance de escolha. As cultivares de hábito rasteiro IAC 147 e IAC Runner 886 afetaram a sobrevivência larval de $S$. bosquella, apresentando resistência do tipo antibiose. Para as cultivares de hábito ereto, IAC 22 e IAC 8112 afetaram a viabilidade larval, apresentando resistência do tipo antibiose. As cultivares de hábito de crescimento rasteiro e ereto não influenciaram os parâmetros biológicos de peso de pupa, razão sexual e longevidade de $S$. bosquella.

Palavras-chave: Arachis hypogaea, lagarta-do-pescoço-vermelho, oleaginosas, resistência de plantas a insetos

\footnotetext{
Abstract

This work aimed to evaluate the attractiveness, non-preference for feeding and antibiosis in straight and runner growth habit peanut cultivars to Stegasta bosquella (Chambers). Eight cultivars were evaluated, four of straight growth habit (IAC Tatu, IAC 22, IAC 8112 and IAC 5) and four of runner growth habit (IAC Runner 886, IAC 147, IAC 125 and IAC 503). Free-choice and no-choice feeding tests were performed, using pairs of overlapped leaf discs with $1.0 \mathrm{~cm}$ diameter, which were placed in Petri dishes where third instar larvae of $S$. bosquella were released. The attractiveness to the larvae was assessed

1 Discente do Curso de Mestrado em Entomologia Agrícola da Faculdade de Ciências Agrárias e Veterinárias, Universidade Estadual Paulista "Júlio de Mesquita Filho", UNESP, Jaboticabal, SP. E-mail: mirellamarconato@hotmail.com

2 Drs. em Entomologia Agrícola pela Faculdade de Ciências Agrárias e Veterinárias, UNESP, Jaboticabal, SP. E-mail: souzabhs@ gmail.com; juliojanini@yahoo.com.br

3 Prof. Dr., Faculdade de Ciências Agrárias e Veterinárias, UNESP, Jaboticabal, SP. E-mail: aboicajr@fcav.unesp.br

* Autor para correspondência
} 
in predetermined times, in addition to the dry mass consumed. In the antibiosis assay, the biological parameters were evaluated: period and viability of larvae, pre-pupae, pupae, and total, weight of larvae and pupae, sex ratio and longevity. None of the runner growth habit cultivars exhibited non-preference for feeding-type resistance. Among the straight growth habit cultivars, IAC 5 and IAC 22 were the least attractive and consumed in the free-choice feeding test, and IAC 5 and IAC 8112 were the least attractive in the no-choice test. The runner growth habit cultivars IAC 147 and IAC Runner 886 affected the larval survival of $S$. bosquella, exhibiting antibiosis-type resistance. For the straight growth habit cultivars, IAC 22 and IAC 8112 affected the larval viability, presenting antibiosis-type resistance. The straight and runner growth habit cultivars did not influence the biological parameters of weight of pupae, sex ratio and longevity of $S$. bosquella.

Key words: Arachis hypogaea, rednecked peanut worm, oilseed, host plant resistance

\section{Introdução}

Na safra 2012/2013 foram produzidas 326 mil toneladas de amendoim (Arachis hypogaea) no Brasil, sendo que a maioria da produção é realizada pelo Estado de São Paulo, representando mais de 90\% da produção do país, dos quais $80 \%$ se destinam ao mercado externo e o restante é utilizado internamente por empresas de doces e confeitos (CONAB, 2014). Nas regiões canavieiras, o amendoinzeiro assume grande importância pelos benefícios advindos na renovação da cultura da cana-de-açúcar, que, pelo fato de ser uma leguminosa, incorpora nitrogênio ao solo, favorecendo a reimplantação da cultura, além de proporcionar renda alternativa da entressafra da cana-de-açúcar (CONAB, 2012).

A exploração da cultura do amendoim é de rentabilidade satisfatória. Entretanto, aumentos adicionais de rentabilidade estão também limitados pelas condições favoráveis do ambiente para a ocorrência de pragas e doenças, fazendo-se necessário o uso do controle químico, onerando os custos da produção (CATI, 1997). A cultura do amendoim pode ser infestada por várias espécies de insetos-pragas. Entre elas, a lagarta-do-pescoçovermelho, Stegasta bosquella (Chambers, 1875) (Lepidoptera: Gelechiidae) é considerada uma das mais importantes pelos prejuízos causados, ocorrência generalizada e elevados níveis populacionais (GALLO et al., 2002; TASSO JUNIOR; MARQUES; NOGUEIRA, 2004; JANINI; SOUZA; BOIÇA JÚNIOR, 2010).

A lagarta se alimenta de folíolos ainda fechados, fazendo na superfície dos mesmos pequenos furos.
As injúrias provocadas pelo ataque desta praga são bastante típicas, de modo que os folíolos novos atacados ao se abrirem exibem lesões simétricas características. Assim, quando as folhas se abrem as lagartas migram para um local abrigado, procurando novos folíolos (MATUO, 1973).

Como alternativa benéfica ao controle químico, o uso de variedades resistentes é considerado como o método ideal, pois mantém a praga abaixo dos níveis de dano econômico, não polui o ambiente, não causa desequilíbrios e reduz o custo do tratamento fitossanitário (LARA, 1991; BOIÇA JÚNIOR et al., 2011a; BOIÇA JÚNIOR et al., 2012). Estudos de resistência foram realizados com o gênero Arachis, visto o potencial demonstrado por algumas de suas espécies silvestres para o melhoramento do amendoim. Muitas das quais possuem níveis de resistência a pragas e doenças superiores aos encontrados em acessos de germoplasma de $A$. hypogaea (STALKER; MOSS, 1987).

Lourenção et al. (2007) concluíram que a cultivar IAC Caiapó apresentou moderada resistência ao tripes Enneothrips flavens Moulton (Thysanoptera: Thripidae). Janini (2009) verificou fontes de resistência à lagarta-do-pescoço-vermelho avaliando a infestação e sintomas desta praga em condições de campo com 44 acessos de 22 espécies silvestres de Arachis, dois anfidiploides e duas cultivares comerciais, nas espécies silvestres $A$. stenosperma, A. cardenasii, A. kuhlmannii, A. hoehnei, A. benensis, A. kempff-mercadoi e $A$. helodes, e observaram menor porcentagem de presença da lagarta e notas visuais de danos em alguns materiais. 
Tendo em vista a importância da lagarta-dopescoço-vermelho para a cultura do amendoim, com relatos de ocorrência de prejuízos econômicos de 64\%, média de 37 lagartas em 72 ramos, e intervalo crítico de 27 dias (43 a 70 dias após a germinação), causados pela sua desfolha (CALCAGNOLO; RENSI; GALLO, 1974), bem como a falta de informação a respeito de cultivares resistentes a esta espécie no Brasil, estudos mais aprofundados são necessários para auxiliar os agricultores no seu controle. Assim, esse trabalho teve como objetivo avaliar possíveis fontes de resistência dos tipos não preferência para alimentação e antibiose em cultivares de amendoim de hábitos de crescimento ereto e rasteiro a $S$. bosquella.

\section{Material e Métodos}

Local dos experimentos, cultivares utilizadas e obtenção dos insetos

Os experimentos foram realizados sem condições de temperatura de $25 \pm 2{ }^{\circ} \mathrm{C}$, umidade relativa de $70 \pm 10 \%$ e fotofase de 12 horas. Foram utilizadas oito cultivares comerciais de amendoim, semeadas em copos plásticos de $500 \mathrm{~mL}$ de volume contendo substrato de terra e esterco na proporção de 3:1. Posteriormente, foram dispostos em casa de vegetação e separados em dois grupos em função de seu hábito de crescimento, sendo quatro rasteiros, IAC Runner 886, IAC 147, IAC 125 e IAC 503, e quatro eretos, IAC Tatu, IAC 22, IAC 8112 e IAC 5.

As lagartas utilizadas nos experimentos foram obtidas da criação estoque, mantida em laboratório e criadas com dieta natural em plantas de amendoinzeiro da cultivar IAC Caiapó. Para o início da criação, coletaram-se lagartas em campo, as quais foram mantidas em placas de Petri até a emergência dos adultos. Em seguida, estes foram acondicionadas em gaiolas constituídas por caixas de vidro com dimensões de $30 \mathrm{~cm}$ de comprimento x $30 \mathrm{~cm}$ de largura x $40 \mathrm{~cm}$ de altura, dentro das quais foram acondicionadas plântulas de amendoim, cultivar IAC Caiapó, com aproximadamente 15 dias de idade, a fim de possibilitar a oviposição. Essas caixas de vidro mantinham a parte superior aberta e coberta com tecido voile e a parte inferior com uma camada de areia (BOIÇA JÚNIOR et al., 2011b).

A manutenção da criação foi realizada diariamente, retirando-se os adultos recémemergidos das gaiolas com as plantas já ovipositadas, e transferindo-os para outra gaiola, de mesmas dimensões, contendo quatro plantas de amendoinzeiro da mesma cultivar e idade.

Teste de não preferência para alimentação com e sem chance de escolha

Para a avaliação da atratividade e não preferência para alimentação das lagartas de S. bosquella em relação às cultivares de amendoim foram realizados testes com e sem chance de escolha. Folíolos jovens das cultivares, ainda fechados, foram coletados aos 30 dias após a emergência das plantas, lavados com solução de hipoclorito de sódio a $0,5 \%$ e água destilada, e em seguida foram preparados discos foliares com auxílio de um vazador com 1,0 cm de diâmetro.

No teste com chance de escolha, pares de discos foliares sobrepostos foram dispostos em placas de Petri de 14,0 cm de diâmetro, revestidas com papel filtro levemente umedecido com água destilada, onde foram liberadas ao centro duas lagartas de terceiro ínstar por cultivar, totalizando oito lagartas por placa. O delineamento experimental utilizado foi o de blocos ao acaso, com seis repetições, sendo que cada repetição foi constituída por uma placa.

Para o teste sem chance de escolha, utilizou-se um par de discos sobrepostos por placa, revestida com papel filtro levemente umedecido com água destilada, onde foi liberada uma lagarta de terceiro ínstar por cultivar. Utilizou-se para este teste o delineamento experimental inteiramente casualizado, com 10 repetições.

Em ambos os testes de não preferência para alimentação, a atratividade das lagartas em relação 
aos discos foliares das cultivares de amendoim foi avaliada a 1, 3, 5, 10, 15, 30, 60, 120, 360 e 720 minutos após a liberação dos insetos, bem como o número de insetos atraídos na média entre esses tempos.

A massa seca consumida (M.S.C.) também foi determinada após o término do experimento. Para isso, o restante dos discos foliares oferecidos às lagartas foram secos em estufa a $60{ }^{\circ} \mathrm{C}$, até atingir massa constante (aproximadamente 48 horas). Previamente à realização dos experimentos, também foram retirados discos foliares, de mesmo diâmetro, provenientes dos folíolos obtidos em duas porções simétricas ao longo da nervura central da planta, utilizando-se uma porção para a preparação dos discos foliares para os experimentos, e a outra como alíquotas. Desse modo, pela diferença entre as massas secas da alíquota e do restante do disco consumido, determinou-se a massa seca (mg) consumida pelo inseto.

Todos os dados obtidos foram analisados quanto à normalidade, transformados em $(\mathrm{x}+0,5)^{1 / 2}$, e em seguida submetidos à análise de variância (ANOVA) pelo teste F, e quando significativo, suas médias foram comparadas pelo teste de Tukey, a 5\% de probabilidade.

\section{Teste de antibiose}

O teste de antibiose foi realizado em placas de Petri de 9,0 cm de diâmetro, revestidas com papel filtro levemente umedecido com água destilada, onde foram transferidas lagartas recém-eclodidas de S. bosquella, na proporção de uma por placa, com o auxílio de um pincel umedecido com água destilada.
Durante todo o período larval, as lagartas foram alimentadas com folíolos das respectivas cultivares de amendoim ad libitum, sendo cessado seu fornecimento quando os insetos atingiram a fase de pupa. Após a emergência dos adultos, os mesmos não receberam qualquer substrato alimentar a fim de serem avaliados apenas os efeitos antibióticos das cultivares no desenvolvimento de S. bosquella.

Os parâmetros biológicos avaliados foram: períodos (dias) e viabilidades (\% de sobrevivência) da fase larval, pré-pupal, pupal e total (eclosão da larva à emergência do adulto), peso das lagartas (mg) com oito dias de idade, peso das pupas (mg) com 24 horas de idade e longevidade dos adultos.

Para o teste de antibiose, utilizou-se o delineamento experimental inteiramente casualizado, com 25 repetições. Os dados foram previamente analisados quanto à normalidade, e aqueles referentes ao peso larval e razão sexual foram transformados em $(x+0,5)^{1 / 2}$ e os de viabilidade larval, pré-pupal, pupal e total foram transformados em arcoseno $(\mathrm{x} / 100)^{1 / 2}$. Em seguida, os dados foram submetidos à análise de variância (ANOVA) pelo teste F, e quando significativo, suas médias foram comparadas pelo teste de Tukey, a 5\% de probabilidade.

\section{Resultados e Discussão}

Teste de não preferência para alimentação com e sem chance de escolha

Em ambos os testes de não preferência para alimentação, a massa seca consumida não diferiu significativamente entre as cultivares de hábito de crescimento rasteiro (Tabelas 1 e 2). 
Tabela 1. Número médio de lagartas de Stegasta bosquella atraídas por cultivares de amendoim de hábito de crescimento rasteiro, em diferentes intervalos de tempo (minutos) após a liberação, e massa seca consumida (M.S.C.) (mg), em teste com chance de escolha. Temp.: $25 \pm 2{ }^{\circ}$ C; U.R.: $70 \pm 10 \%$; Fotofase: 12 horas. Jaboticabal, SP, 2011.

\begin{tabular}{|c|c|c|c|c|c|c|}
\hline \multirow{2}{*}{ Cultivares } & \multicolumn{6}{|c|}{ Tempos $^{1}$} \\
\hline & 1 ' & $3^{\prime}$ & 5 , & $10^{\prime}$ & $15^{\prime}$ & $30^{\prime}$ \\
\hline IAC Runner 886 & $0,00 \pm 0,00 \mathrm{~b}$ & $0,00 \pm 0,00 \mathrm{~b}$ & $0,00 \pm 0,00 \mathrm{~b}$ & $0,25 \pm 0,25$ & $0,25 \pm 0,25$ & $0,25 \pm 0,25$ \\
\hline IAC 147 & $0,50 \pm 0,29 \mathrm{ab}$ & $0,50 \pm 0,29 \mathrm{ab}$ & $0,50 \pm 0,29 \mathrm{ab}$ & $0,75 \pm 0,25$ & $0,50 \pm 0,29$ & $0,50 \pm 0,29$ \\
\hline IAC 125 & $1,00 \pm 0,41 \mathrm{a}$ & $1,00 \pm 0,41 \mathrm{a}$ & $1,00 \pm 0,41^{\mathrm{a}}$ & $0,75 \pm 0,48$ & $1,00 \pm 0,41$ & $1,00 \pm 0,41$ \\
\hline IAC 503 & $0,00 \pm 0,00 \mathrm{~b}$ & $0,00 \pm 0,00 \mathrm{~b}$ & $0,00 \pm 0,00 \mathrm{~b}$ & $0,25 \pm 0,25$ & $0,25 \pm 0,25$ & $0,25 \pm 0,25$ \\
\hline $\mathrm{F}$ & $5,04^{*}$ & $5,04^{*}$ & $5,04^{*}$ & $1,24^{\mathrm{NS}}$ & $2,08^{\mathrm{NS}}$ & $2,08^{\mathrm{NS}}$ \\
\hline C.V. $(\%)$ & 23,03 & 23,03 & 23,03 & 26,08 & 23,83 & 23,83 \\
\hline \multirow{2}{*}{ Cultivares } & \multicolumn{6}{|c|}{ Tempos $^{1}$} \\
\hline & $60^{\prime}$ & $120^{\prime}$ & $360^{\prime}$ & $720^{\prime}$ & Média $^{1}$ & M.S.C. $(\mathrm{mg})^{1}$ \\
\hline IAC Runner 886 & $0,50 \pm 0,50$ & $0,50 \pm 0,50$ & $0,50 \pm 0,29$ & $0,75 \pm 0,25$ & $0,30 \pm 0,09 \mathrm{~b}$ & $0,55 \pm 0,33$ \\
\hline IAC 147 & $0,75 \pm 0,25$ & $0,75 \pm 0,25$ & $1,25 \pm 0,63$ & $1,00 \pm 0,41$ & $0,70 \pm 0,10 \mathrm{ab}$ & $0,38 \pm 0,23$ \\
\hline IAC 125 & $0,75 \pm 0,25$ & $1,25 \pm 0,48$ & $0,75 \pm 0,25$ & $1,25 \pm 0,25$ & $0,98 \pm 0,11 \mathrm{a}$ & $0,73 \pm 0,32$ \\
\hline IAC 503 & $0,75 \pm 0,48$ & $0,75 \pm 0,25$ & $0,75 \pm 0,25$ & $1,25 \pm 0,63$ & $0,43 \pm 0,11 \mathrm{bc}$ & $0,73 \pm 0,32$ \\
\hline $\mathrm{F}$ & $0,20^{\mathrm{NS}}$ & $0,65^{\mathrm{NS}}$ & $0,43^{\mathrm{NS}}$ & $0,26^{\mathrm{NS}}$ & $11,89^{* *}$ & $0,36^{\mathrm{NS}}$ \\
\hline C.V.(\%) & 34,55 & 32,20 & 32,83 & 30,56 & 26,52 & 0,06 \\
\hline
\end{tabular}

${ }^{1}$ Médias seguidas de mesma letra, na coluna, não diferem significativamente entre si pelo teste de Tukey, a $5 \%$ de probabilidade. Para análise, os dados foram transformados em $(x+0,5)^{1 / 2}$. NS $=$ não significativo; $*$ = significativo a $5 \% ; * *=$ significativo a $1 \%$.

Fonte: Elaboração dos autores.

Em teste com chance de escolha com as cultivares de amendoim de hábito de crescimento rasteiro, observou-se que nos tempos de 1, 3 e 5 minutos após a liberação das lagartas, a cultivar IAC 125 se mostrou mais atrativa em relação a IAC Runner 886 e IAC 503, que não apresentaram insetos atraídos nos tempos citados. Nos demais períodos de avaliação, o número de lagartas atraídas não diferiu significativamente entre as cultivares (Tabela 1).

Boiça Júnior et al. (2008), em teste de não preferência para alimentação com chance de escolha por Anticarsia gemmatalis Hübner (Lepidoptera: Erebidae), não verificaram diferença significativa no número de lagartas atraídas por cultivares de amendoim, todavia, na área foliar consumida, as cultivares IAC Caiapó, IAC Runner 886 e IAC 147 foram menos preferidas para alimentação, demonstrando apresentar fatores de resistência à lagarta-da-soja, não se assemelhando ao presente trabalho que obteve resultados diferentes.

Na média dos tempos avaliados, verifica-se que houve diferença significativa na atratividade entre as cultivares de amendoinzeiro. A cultivar IAC 125 apresentou uma média de 0,98 lagartas atraídas, enquanto IAC Runner 886 obteve uma média de 0,30 lagartas, mostrando-se a menos atrativa (Tabela 1).

Para o teste sem chance de escolha, as cultivares não diferiram significativamente entre si, em qualquer intervalo de tempo, avaliando a atratividade, porém, na média dos tempos de avaliação, as cultivares IAC 147 e IAC Runner 886 foram a mais e menos atrativa, com médias de 0,72 e 0,53 lagartas, respectivamente (Tabela 2). 
Tabela 2. Número médio de lagartas de Stegasta bosquella atraídas por cultivares de amendoim de hábito de crescimento rasteiro, em diferentes intervalos de tempo (minutos) após a liberação, e massa seca consumida (M.S.C.) (mg), em teste sem chance de escolha. Temp.: $25 \pm 2{ }^{\circ}$ C; U.R.: $70 \pm 10 \%$; Fotofase: 12 horas. Jaboticabal, SP, 2011.

\begin{tabular}{ccccccc}
\hline \multirow{2}{*}{ Cultivares } & \multicolumn{7}{c}{ Tempos $^{1}$} \\
\cline { 2 - 7 } & $1^{\prime}$ & $3^{\prime}$ & $5^{\prime}$ & $10^{\prime}$ & $15^{\prime}$ & $30^{\prime}$ \\
\hline IAC Runner 886 & $0,50 \pm 0,17$ & $0,50 \pm 0,17$ & $0,50 \pm 0,17$ & $0,50 \pm 0,17$ & $0,50 \pm 0,17$ & $0,50 \pm 0,17$ \\
IAC 147 & $0,50 \pm 0,17$ & $0,50 \pm 0,17$ & $0,60 \pm 0,16$ & $0,60 \pm 0,16$ & $0,60 \pm 0,16$ & $0,60 \pm 0,16$ \\
IAC 125 & $0,30 \pm 0,15$ & $0,30 \pm 0,15$ & $0,30 \pm 0,15$ & $0,40 \pm 0,16$ & $0,70 \pm 0,15$ & $0,80 \pm 0,13$ \\
IAC 503 & $0,40 \pm 0,16$ & $0,40 \pm 0,16$ & $0,50 \pm 0,17$ & $0,60 \pm 0,16$ & $0,60 \pm 0,16$ & $0,60 \pm 0,16$ \\
\hline F & $0,35^{\mathrm{NS}}$ & $0,35^{\mathrm{NS}}$ & $0,60^{\mathrm{NS}}$ & $0,34^{\mathrm{NS}}$ & $0,26^{\mathrm{NS}}$ & $0,64^{\mathrm{NS}}$ \\
C.V.(\%) & 28,68 & 28,68 & 27,90 & 27,45 & 25,99 & 24,97 \\
\hline Cultivares & \multicolumn{7}{c}{ Tempos $^{1}$} & \multicolumn{3}{c}{} \\
\cline { 2 - 7 } IAC Runner 886 & $0,50 \pm 0,17$ & $0,50 \pm 0,17$ & $0,60 \pm 0,16$ & $0,70 \pm 0,15$ & $0,53 \pm 0,05 \mathrm{~b}$ & $0,64 \pm 0,16$ \\
IAC 147 & $0,90 \pm 0,10$ & $0,90 \pm 0,10$ & $1,00 \pm 0,00$ & $1,00 \pm 0,00$ & $0,72 \pm 0,05 \mathrm{a}$ & $0,54 \pm 0,14$ \\
IAC 125 & $0,80 \pm 0,13$ & $0,90 \pm 0,10$ & $0,80 \pm 0,13$ & $0,70 \pm 0,15$ & $0,60 \pm 0,05 \mathrm{ab}$ & $0,47 \pm 0,13$ \\
IAC 503 & $0,70 \pm 0,15$ & $0,80 \pm 0,13$ & $0,60 \pm 0,16$ & $0,80 \pm 0,13$ & $0,60 \pm 0,05 \mathrm{ab}$ & $0,53 \pm 0,15$ \\
\hline F & $1,48^{\mathrm{NS}}$ & $2,19^{\mathrm{NS}}$ & $2,06^{\mathrm{NS}}$ & $1,24^{\mathrm{NS}}$ & $2,65^{*}$ & $0,24^{\mathrm{NS}}$ \\
C.V.(\%) & 21,24 & 18,91 & 19,93 & 18,53 & 24,50 & 0,05 \\
\hline
\end{tabular}

${ }^{1}$ Médias seguidas de mesma letra, na coluna, não diferem significativamente entre si pelo teste de Tukey, a 5\% de probabilidade. Para análise, os dados foram transformados em $(x+0,5)^{1 / 2}$. NS $=$ não significativo; $*$ = significativo a $5 \%$.

Fonte: Elaboração dos autores.

Em teste sem chance de escolha para cultivares de amendoim de hábito de crescimento rasteiro a Spodoptera cosmioides (Walker) (Lepidoptera: Noctuidae), Boiça Júnior et al. (2013) observaram diferença significativa entre as cultivares IAC 503 e IAC 147, as quais mostraram-se respectivamente a mais e a menos atrativa em relação às demais.

Para as cultivares de hábito de crescimento ereto, no teste com chance de escolha, não houve diferença significativa na atratividade de lagartas de S. bosquella nos tempos de avaliação. Entretanto, ao se analisar a média entre os tempos, a cultivar IAC 8112 obteve uma média de 1,10 lagartas, diferindo significativamente da IAC 5 e IAC 22, que apresentaram médias de 0,50 e 0,60 lagartas, respectivamente (Tabela 3 ).
No teste sem chance de escolha, houve diferença significativa apenas na média dos tempos (Tabela 4). A cultivar IAC 22 foi mais atrativa em relação às cultivares IAC 8112 e IAC 5, todavia, não diferiu significativamente da cultivar IAC Tatu. Por outro lado, as cultivares IAC 8112 e IAC 5 não diferiram entre si e em relação a IAC Tatu, porém, comportaram-se como menos atrativas que IAC 22.

A massa seca consumida pelas lagartas no teste com chance de escolha apresentou diferença significativa entre cultivares (Tabela 3 ). A cultivares IAC Tatu e IAC 8112 tiveram consumo médio de 1,30 e 1,23 mg, respectivamente, sendo mais consumidas em relação a IAC 22 e IAC 5, as quais apresentaram consumo foliar de 0,40 e $0,28 \mathrm{mg}$, respectivamente, e não deferiram entre si. No teste sem chance de escolha, não houve diferença significativa entre as cultivares de hábito de crescimento ereto (Tabela 4). 
Tabela 3. Número médio de lagartas de Stegasta bosquella atraídas por cultivares de amendoim de hábito de crescimento ereto, em diferentes intervalos de tempo (minutos) após a liberação, e massa seca consumida (M.S.C.) (mg), em teste com chance de escolha. Temp.: $25 \pm 2{ }^{\circ}$ C; U.R.: $70 \pm 10 \%$; Fotofase: 12 horas. Jaboticabal, SP, 2011.

\begin{tabular}{ccccccc}
\hline \multirow{2}{*}{ Cultivares } & \multicolumn{7}{c}{ Tempos $^{1}$} \\
\cline { 2 - 7 } & $1^{\prime}$ & $3^{\prime}$ & $5^{\prime}$ & $10^{\prime}$ & $15^{\prime}$ & $30^{\prime}$ \\
\hline IAC Tatu & $0,75 \pm 0,25$ & $0,75 \pm 0,25$ & $0,75 \pm 0,25$ & $0,75 \pm 0,25$ & $0,75 \pm 0,25$ & $0,75 \pm 0,25$ \\
IAC 22 & $0,50 \pm 0,29$ & $0,50 \pm 0,29$ & $0,50 \pm 0,29$ & $0,50 \pm 0,29$ & $0,50 \pm 0,29$ & $0,50 \pm 0,29$ \\
IAC 8112 & $0,75 \pm 0,25$ & $1,25 \pm 0,25$ & $1,00 \pm 0,00$ & $1,25 \pm 0,25$ & $1,25 \pm 0,25$ & $1,25 \pm 0,25$ \\
IAC 5 & $0,50 \pm 0,29$ & $0,25 \pm 0,25$ & $0,25 \pm 0,25$ & $0,25 \pm 0,25$ & $0,25 \pm 0,25$ & $0,50 \pm 0,29$ \\
\hline F & $0,27^{\mathrm{NS}}$ & $3,02^{\mathrm{NS}}$ & $2,14^{\mathrm{NS}}$ & $3,02^{\mathrm{NS}}$ & $3,02^{\mathrm{NS}}$ & $2,59^{\mathrm{NS}}$ \\
C.V.(\%) & 27,76 & 22,26 & 22,15 & 22,26 & 22,26 & 18,80 \\
\hline \multirow{2}{*}{ Cultivares } & \multicolumn{7}{c}{ Tempos $^{1}$} \\
\cline { 2 - 7 } & $60^{\prime}$ & $120^{\prime}$ & $360^{\prime}$ & $720^{\prime}$ & Média $^{1}$ & M.S.C. $(\mathrm{mg})^{1}$ \\
\hline IAC Tatu & $0,75 \pm 0,25$ & $1,00 \pm 0,00$ & $1,00 \pm 0,00$ & $1,00 \pm 0,00$ & $0,83 \pm 0,06 \mathrm{ab}$ & $1,30 \pm 0,18 \mathrm{a}$ \\
IAC 22 & $0,50 \pm 0,29$ & $0,50 \pm 0,29$ & $0,75 \pm 0,25$ & $1,25 \pm 0,48$ & $0,60 \pm 0,09 \mathrm{bc}$ & $0,40 \pm 0,14 \mathrm{~b}$ \\
IAC 8112 & $1,00 \pm 0,00$ & $1,00 \pm 0,00$ & $1,25 \pm 0,25$ & $1,00 \pm 0,00$ & $1,10 \pm 0,06 \mathrm{a}$ & $1,23 \pm 0,28 \mathrm{a}$ \\
IAC 5 & $0,50 \pm 0,29$ & $0,75 \pm 0,48$ & $1,00 \pm 0,48$ & $0,75 \pm 0,48$ & $0,50 \pm 0,11 \mathrm{c}$ & $0,28 \pm 0,24 \mathrm{~b}$ \\
\hline F & $1,32^{\mathrm{NS}}$ & $1,06^{\mathrm{NS}}$ & $0,45^{\mathrm{NS}}$ & $0,45^{\mathrm{NS}}$ & $14,22^{* *}$ & $4,95^{*}$ \\
C.V.(\%) & 20,29 & 22,43 & 23,95 & 23,95 & 21,02 & 0,05 \\
\hline
\end{tabular}

${ }^{1}$ Médias seguidas de mesma letra, na coluna, não diferem significativamente entre si pelo teste de Tukey, a 5\% de probabilidade. Para análise, os dados foram transformados em $(x+0,5)^{1 / 2}$. NS $=$ não significativo; $*$ = significativo a $5 \%$; ** = significativo a $1 \%$.

Fonte: Elaboração dos autores.

Tabela 4. Número médio de lagartas de Stegasta bosquella atraídas por cultivares de amendoim de hábito de crescimento ereto, em diferentes intervalos de tempo (minutos) após a liberação, e massa seca consumida (M.S.C.) (mg), em teste sem chance de escolha. Temp.: $25 \pm 2{ }^{\circ} \mathrm{C}$; U.R.: $70 \pm 10 \%$; Fotofase: 12 horas. Jaboticabal, SP, 2011.

\begin{tabular}{ccccccc}
\hline \multirow{2}{*}{ Cultivares } & \multicolumn{7}{c}{ Tempos $^{1}$} \\
\cline { 2 - 7 } & $1^{\prime}$ & $3^{\prime}$ & $5^{\prime}$ & 10 & $15^{\prime}$ & $30^{\prime}$ \\
\hline IAC Tatu & $0,50 \pm 0,17$ & $0,60 \pm 0,16$ & $0,60 \pm 0,16$ & $0,60 \pm 0,16$ & $0,60 \pm 0,16$ & $0,60 \pm 0,16$ \\
IAC 22 & $0,60 \pm 0,16$ & $0,70 \pm 0,15$ & $0,70 \pm 0,15$ & $0,80 \pm 0,13$ & $0,80 \pm 0,13$ & $0,80 \pm 0,13$ \\
IAC 8112 & $0,40 \pm 0,16$ & $0,40 \pm 0,16$ & $0,40 \pm 0,16$ & $0,40 \pm 0,16$ & $0,40 \pm 0,16$ & $0,40 \pm 0,16$ \\
IAC 5 & $0,50 \pm 0,17$ & $0,50 \pm 0,17$ & $0,50 \pm 0,17$ & $0,50 \pm 0,17$ & $0,50 \pm 0,17$ & $0,50 \pm 0,17$ \\
\hline F & $0,25^{\mathrm{NS}}$ & $0,64^{\mathrm{NS}}$ & $0,64^{\mathrm{NS}}$ & $1,18^{\mathrm{NS}}$ & $1,18^{\mathrm{NS}}$ & $1,18^{\mathrm{NS}}$ \\
C.V.(\%) & 27,96 & 26,67 & 26,67 & 25,62 & 25,62 & 25,62 \\
\hline \multirow{2}{*}{ Cultivares } & \multicolumn{7}{c}{ Tempos $^{1}$} & \multicolumn{3}{c}{} \\
\cline { 2 - 7 } & $60^{\prime}$ & $120^{\prime}$ & $360^{\prime}$ & $720^{\prime}$ & Média $^{1}$ & M.S.C. $(\mathrm{mg})^{1}$ \\
\hline IAC Tatu & $0,60 \pm 0,16$ & $0,60 \pm 0,16$ & $0,60 \pm 0,16$ & $0,60 \pm 0,16$ & $0,59 \pm 0,05 \mathrm{ab}$ & $0,51 \pm 0,14$ \\
IAC 22 & $0,80 \pm 0,13$ & $0,80 \pm 0,13$ & $0,80 \pm 0,13$ & $0,80 \pm 0,13$ & $0,76 \pm 0,04 \mathrm{a}$ & $0,41 \pm 0,12$ \\
IAC 8112 & $0,40 \pm 0,16$ & $0,40 \pm 0,16$ & $0,60 \pm 0,16$ & $0,60 \pm 0,16$ & $0,44 \pm 0,05 \mathrm{~b}$ & $0,32 \pm 0,12$ \\
IAC 5 & $0,60 \pm 0,16$ & $0,60 \pm 0,16$ & $0,70 \pm 0,15$ & $0,70 \pm 0,15$ & $0,56 \pm 0,04 \mathrm{~b}$ & $0,36 \pm 0,14$ \\
\hline F & $1,09^{\mathrm{NS}}$ & $1,09^{\mathrm{NS}}$ & $0,39^{\mathrm{NS}}$ & $0,39^{\mathrm{NS}}$ & $7,52^{* *}$ & $0,39^{\mathrm{NS}}$ \\
C.V.(\%) & 25,15 & 25,15 & 23,81 & 23,81 & 24,63 & 0,04 \\
\hline
\end{tabular}

${ }^{1}$ Médias seguidas de mesma letra, na coluna, não diferem significativamente entre si pelo teste de Tukey, a 5\% de probabilidade. Para análise, os dados foram transformados em $(x+0,5)^{1 / 2}$. NS $=$ não significativo; $* *=$ significativo a $1 \%$.

Fonte: Elaboração dos autores. 
Avaliando a resistência de cultivares de amendoim de crescimento rasteiro a $A$. gemmatalis, Boiça Júnior et al. (2008) não observaram diferenças quanto à atratividade das lagartas, no entanto, para o consumo foliar, IAC 147, IAC Caiapó e IAC Runner 886 destacaram-se como os menos preferidos para a alimentação, em testes com e sem chance de escolha.

Campos, Boiça Júnior e Ribeiro (2010), avaliando cultivares de amendoim de hábito de crescimento rasteiro (IAC 5, IAC 8112, IAC 22 e IAC Tatu ST) e ereto (IAC 503, IAC 505, IAC 147, IAC 125, IAC Caiapó e IAC Runner 886), não observaram diferenças significativas na atratividade e consumo foliar de Spodoptera frugiperda (J. E. Smith) (Lepidoptera: Noctuidae) em teste sem chance de escolha.

\section{Teste de antibiose}

Analisando-se os dados obtidos a partir das avaliações dos parâmetros biológicos de $S$. bosquella, pode-se verificar que não houve efeito significativo das cultivares de amendoim de hábito de crescimento rasteiro na duração dos períodos larval, de pré-pupa, pupal, total e longevidade dos adultos (Tabela 5).

Tabela 5. Duração (dias) dos períodos larval, de pré-pupa, pupal e total e viabilidade (\%) larval, de pré-pupa, pupal e total de Stegasta bosquella, alimentada com quatro cultivares de amendoim de hábito de crescimento rasteiro. Temperatura: $25 \pm 1{ }^{\circ} \mathrm{C}$; U.R..: $70 \pm 10 \%$; Fotofase: 12 horas. Jaboticabal, SP, 2011.

\begin{tabular}{|c|c|c|c|c|c|c|c|c|}
\hline Cultivares & $\begin{array}{l}\text { Período } \\
\text { Larval }^{1}\end{array}$ & $\begin{array}{l}\text { Viabilidade } \\
\text { Larval }^{1}\end{array}$ & $\begin{array}{l}\text { Período de } \\
\text { Pré-Pupa }^{1}\end{array}$ & $\begin{array}{l}\text { Viabilidade } \\
\text { Pré-Pupal }^{1}\end{array}$ & $\begin{array}{l}\text { Período } \\
\text { Pupal }^{1}\end{array}$ & $\begin{array}{c}\text { Viabilidade } \\
\text { Pupal }^{1}\end{array}$ & $\begin{array}{c}\text { Período } \\
\text { Total }^{1}\end{array}$ & $\begin{array}{l}\text { Viabilidade } \\
\text { Total }^{1}\end{array}$ \\
\hline IAC 503 & $13,00 \pm 0,53$ & $72,00 \pm 9,17 \mathrm{a}$ & $1,28 \pm 0,11$ & $36,00 \pm 9,80$ & $7,38 \pm 0,33$ & $52,00 \pm 10,20$ & $22,00 \pm 0,93$ & $52,00 \pm 10,20 \mathrm{ab}$ \\
\hline IAC 147 & $13,22 \pm 0,94$ & $36,00 \pm 9,80 \mathrm{~b}$ & $1,78 \pm 0,22$ & $36,00 \pm 9,80$ & $7,14 \pm 0,40$ & $28,00 \pm 9,17$ & $23,00 \pm 1,35$ & $28,00 \pm 9,17 \mathrm{ab}$ \\
\hline $\begin{array}{l}\text { IAC Runner } \\
\quad 886\end{array}$ & $12,00 \pm 0,73$ & $32,00 \pm 9,80 \mathrm{~b}$ & $1,50 \pm 0,27$ & $32,00 \pm 9,52$ & $7,43 \pm 0,17$ & $24,00 \pm 8,72$ & $21,40 \pm 1,02$ & $20,00 \pm 8,17 \mathrm{~b}$ \\
\hline IAC 125 & $13,93 \pm 0,37$ & $60,00 \pm 10,00 \mathrm{ab}$ & $1,73 \pm 0,12$ & $60,00 \pm 10,00$ & $7,83 \pm 0,23$ & $56,00 \pm 10,13$ & $22,93 \pm 0,42$ & $56,00 \pm 10,13 \mathrm{a}$ \\
\hline $\mathrm{F}$ & $1,49^{\mathrm{NS}}$ & $3,97 *$ & $2,52^{\mathrm{NS}}$ & $1,71^{\mathrm{NS}}$ & $0,55^{\mathrm{NS}}$ & $2,91^{\mathrm{NS}}$ & $0,57^{\mathrm{NS}}$ & $3,51 *$ \\
\hline C.V. (\%) & 16,18 & 96,26 & 35,95 & 119,28 & 13,13 & 119,68 & 12,47 & 121,17 \\
\hline
\end{tabular}

${ }^{1}$ Médias seguidas de mesma, letra, na coluna, não diferem significativamente pelo teste de Tukey, a $5 \%$ de probabilidade. Para análise, os dados foram transformados em $\operatorname{arcoseno}(\mathrm{x} / 100)^{1 / 2}$. ${ }^{\mathrm{NS}}=$ não significativo; $* *=$ significativo a $1 \%$.

Fonte: Elaboração dos autores.

Campos et al. (2011), estudando os aspectos biológicos de $S$. frugiperda criadas em diferentes cultivares de amendoinzeiro, observaram que IAC Runner 886 proporcionou maior duração da fase larval (21,04 dias) quando comparado a IAC 503, IAC 505 e IAC 125. No mesmo trabalho, os autores verificaram que as cultivares IAC 147 e IAC Caiapó apresentaram valores intermediários na duração da fase larval, sendo isso diferente do encontrado neste trabalho.

Em relação à viabilidade das fases biológicas da lagarta-do-pescoço-vermelho, pode-se observar diferenças significativas na viabilidade larval, onde a cultivar IAC 503 apresentou o maior índice de sobrevivência, 72,00\%, ao contrário de IAC Runner 886 e IAC 147, que demonstraram baixa viabilidade larval, 32,00 e 36,00\%, respectivamente (Tabela 5). Esses dados corroboram os resultados obtidos por Campos et al. (2011), que demonstraram que a cultivar IAC Runner 886 também afetou a biologia de $S$. frugiperda, cujas lagartas apresentaram índice de viabilidade de $60,00 \%$, comparativamente a IAC 503, que apresentou 96,00\%.

Os parâmetros de viabilidades de pré-pupa e de pupa não foram influenciados significativamente pelas cultivares de hábito de crescimento rasteiro de amendoim (Tabela 5). 
As cultivares de amendoinzeiro também influenciaram significativamente a viabilidade do ciclo total de $S$. bosquella, de maneira que, as lagartas que se alimentaram com folíolos do cultivar IAC Runner 886 tiveram baixo índice de sobrevivência durante o desenvolvimento completo, $20,00 \%$, diferindo significativamente de IAC 125 , que obteve $56,00 \%$ de viabilidade (Tabela 5).

Boiça Júnior et al. (2013), avaliando os mesmos parâmetros biológicos, referentes aos períodos e viabilidades em cultivares de amendoim de hábito de crescimento ereto com $S$. cosmioides, observaram diferença significativa apenas no período total, sendo que a cultivar IAC 8112 prolongou o ciclo de S. cosmioides em relação às cultivares IAC 22 , IAC Tatu ST e IAC 5, as quais não diferiram entre si.

O peso de lagartas com oito dias de idade, pupas com 24 horas de idade e razão sexual não diferiram significativamente entre as cultivares de amendoim de hábito de crescimento rasteiro (Tabela 6).

Tabela 6. Peso (mg) larval e pupal, razão sexual e longevidade (dias) de adultos de Stegasta bosquella, alimentada com quatro cultivares de amendoim de hábito de crescimento rasteiro. Temperatura: $25 \pm 1{ }^{\circ} \mathrm{C}$; U.R..: $70 \pm 10 \%$; Fotofase: 12 horas. Jaboticabal, SP, 2011.

\begin{tabular}{ccccc}
\hline Cultivares & Peso Larval $^{1,2}$ & Peso Pupal $^{1}$ & RazãoSexual $^{1,2}$ & Longevidade $^{1}$ \\
\hline IAC 503 & $3,59 \pm 0,43$ & $3,35 \pm 0,25$ & $0,56 \pm 0,13$ & $3,46 \pm 0,29$ \\
IAC 147 & $2,89 \pm 0,75$ & $4,29 \pm 0,24$ & $0,50 \pm 0,19$ & $3,14 \pm 0,65$ \\
IAC Runner 886 & $3,09 \pm 0,59$ & $4,34 \pm 0,29$ & $0,50 \pm 0,19$ & $4,20 \pm 0,66$ \\
IAC 125 & $1,85 \pm 0,29$ & $4,10 \pm 0,22$ & $0,53 \pm 0,13$ & $3,78 \pm 0,24$ \\
\hline F & $2,89^{\mathrm{NS}}$ & $3,47^{\mathrm{NS}}$ & $0,04^{\mathrm{NS}}$ & $1,18^{\mathrm{NS}}$ \\
C.V. $(\%)$ & 0,18 & 23,36 & 27,45 & 29,29 \\
\hline
\end{tabular}

${ }^{1}$ Médias seguidas de mesma letra, na coluna, não diferem significativamente pelo teste de Tukey, a $5 \%$ de probabilidade. ${ }^{2}$ Para análise, os dados foram transformados em $(x+0,5)^{1 / 2} \cdot{ }^{\text {NS }}=$ não significativo.

Fonte: Elaboração dos autores.

Analisando-se os dados do desenvolvimento biológico da lagarta-do-pescoço-vermelho em cultivares de amendoim de hábito de crescimento ereto, pode-se observar que na duração dos períodos larval, de pré-pupa, pupal, total e longevidade de adultos, não houve diferença significativa entre cultivares avaliadas (Tabela 7).

Dentre as cultivares avaliadas, lagartas alimentadas com folíolos de IAC 22 demonstraram baixa viabilidade larval, com apenas 12,00\%, enquanto aquelas criadas com as cultivares IAC 5 e IAC Tatu apresentaram altos índices de sobrevivência, com 80,00 e $52,00 \%$, respectivamente (Tabela 7). Na avaliação da viabilidade de prépupa, também se observou menor mortalidade nas cultivares IAC 5 e IAC Tatu e maiores em IAC 22 e IAC 8112 (Tabela 7). Campos et al. (2011) observaram que, dentre as cultivares de hábito de crescimento ereto, IAC 22 foi a menos adequada ao desenvolvimento da lagarta-militar S.frugiperda, apresentando resistência moderada do tipo antibiose. Nos parâmetros de viabilidade pupal e total, não houve diferença significativa entre as cultivares (Tabela 7).

O peso de lagartas de $S$. bosquella com oito dias de idade apresentou diferença significativa entre as cultivares IAC 22, IAC 8112 e IAC Tatu (Tabela 8). Lagartas alimentadas com folíolos de IAC 22 apresentaram maior peso, $3,37 \mathrm{mg}$, em comparação àquelas criadas com IAC 8112 e IAC Tatu, cujos valores foram de 0,89 e 1,26 mg, respectivamente. O peso de pupas com 24 horas de idade e razão sexual não diferiram significativamente entre as cultivares de amendoinzeiro (Tabela 8). 
Tabela 7. Duração média (dias) dos períodos larval, de pré-pupa, pupal, total e viabilidade (\%) larval, de pré-pupa, pupal e total de Stegasta bosquella, alimentadas com quatro cultivares de amendoim de hábito de crescimento ereto. Temperatura: $25 \pm 1{ }^{\circ} \mathrm{C}$; U.R..: $70 \pm 10 \%$; Fotofase: 12 horas. Jaboticabal, SP, 2011.

\begin{tabular}{ccccccccc}
\hline Cultivares & $\begin{array}{c}\text { Período } \\
\text { Larval }^{1}\end{array}$ & $\begin{array}{c}\text { Viabilidade } \\
\text { Larval }^{1}\end{array}$ & $\begin{array}{c}\text { Período de } \\
\text { Pré-Pupa }^{1}\end{array}$ & $\begin{array}{c}\text { Viabilidade Pré- } \\
\text { Pupal }^{1}\end{array}$ & $\begin{array}{c}\text { Período } \\
\text { Pupal }^{1}\end{array}$ & $\begin{array}{c}\text { Viabilidade } \\
\text { Pupal }^{1}\end{array}$ & $\begin{array}{c}\text { Período } \\
\text { Total }^{1}\end{array}$ & $\begin{array}{c}\text { Viabilidade } \\
\text { Total }^{1}\end{array}$ \\
\hline IAC 8112 & $15,33 \pm 1,13$ & $36,00 \pm 9,80 \mathrm{bc}$ & $2,14 \pm 0,26$ & $28,00 \pm 9,17 \mathrm{ab}$ & $7,20 \pm 0,21$ & $24,00 \pm 8,72$ & $24,17 \pm 1,49$ & $28,00 \pm 9,17$ \\
IAC Tatu & $14,15 \pm 0,70$ & $52,00 \pm 10,20 \mathrm{ab}$ & $2,00 \pm 0,20$ & $52,00 \pm 10,20 \mathrm{a}$ & $7,45 \pm 0,25$ & $44,00 \pm 10,13$ & $23,27 \pm 0,82$ & $48,00 \pm 10,20$ \\
IAC 5 & $17,10 \pm 0,63$ & $80,00 \pm 8,16 \mathrm{a}$ & $2,17 \pm 0,17$ & $48,00 \pm 10,20 \mathrm{a}$ & $6,86 \pm 0,14$ & $28,00 \pm 9,17$ & $25,14 \pm 0,70$ & $52,00 \pm 10,20$ \\
IAC 22 & $15,33 \pm 1,86$ & $12,00 \pm 6,63 \mathrm{c}$ & $1,67 \pm 0,33$ & $12,00 \pm 6,63 \mathrm{~b}$ & $7,33 \pm 0,50$ & $12,00 \pm 6,63$ & $22,33 \pm 0,50$ & $12,00 \pm 6,63$ \\
\hline F & $2,46^{\mathrm{NS}}$ & $10,49^{* *}$ & $0,55^{\mathrm{NS}}$ & $4,11^{* *}$ & $1,27^{\mathrm{NS}}$ & $2,28^{\mathrm{NS}}$ & $1,08^{\mathrm{NS}}$ & $2,28^{\mathrm{NS}}$ \\
C.V. $(\%)$ & 17,46 & 97,92 & 31,71 & 130,93 & 8,87 & 162,15 & 11,15 & 162,15 \\
\hline
\end{tabular}

${ }^{1}$ Médias seguidas de mesma letra, na coluna, não diferem significativamente pelo teste de Tukey, a $5 \%$ de probabilidade. Para análise, os dados foram transformados em arcoseno $(\mathrm{x} / 100)^{1 / 2}$. ${ }^{\mathrm{NS}}=$ não significativo; $* *=$ significativo a $1 \%$.

Fonte: Elaboração dos autores.

Tabela 8. Pesos (mg) larval e pupal, razão sexual e longevidade (dias) de adultos de Stegasta bosquella, alimentada com quatro cultivares de amendoim de hábito de crescimento ereto. Temperatura: $25 \pm 1{ }^{\circ} \mathrm{C}$; U.R..: $70 \pm 10 \%$; Fotofase: 12 horas. Jaboticabal, SP, 2011.

\begin{tabular}{ccccc}
\hline Cultivares & Peso Larval ${ }^{1,2}$ & Peso Pupal $^{1}$ & Razão Sexual $^{1,2}$ & Longevidade $^{1}$ \\
\hline IAC 8112 & $0,89 \pm 0,39 \mathrm{~b}$ & $4,43 \pm 0,38$ & $0,33 \pm 0,17$ & $4,60 \pm 0,43$ \\
IAC Tatu & $1,26 \pm 0,34 \mathrm{~b}$ & $4,50 \pm 0,17$ & $0,42 \pm 0,15$ & $4,27 \pm 0,27$ \\
IAC 5 & $2,68 \pm 0,46 \mathrm{ab}$ & $4,16 \pm 0,15$ & $0,43 \pm 0,20$ & $3,86 \pm 0,26$ \\
IAC 22 & $3,37 \pm 1,01 \mathrm{a}$ & $4,30 \pm 0,25$ & $0,67 \pm 0,33$ & $3,00 \pm 0,00$ \\
\hline F & $5,14^{* *}$ & $0,61^{\mathrm{NS}}$ & $0,31^{\mathrm{NS}}$ & $2,53^{\mathrm{NS}}$ \\
C.V. (\%) & 0,17 & 14,71 & 29,12 & 21,07 \\
\hline
\end{tabular}

${ }^{1}$ Médias seguidas de mesma letra, na coluna, não diferem significativamente pelo teste de Tukey, a $5 \%$ de probabilidade. ${ }^{2}$ Para análise, os dados foram transformados em $(\mathrm{x}+0,5)^{1 / 2} \cdot{ }^{\mathrm{NS}}=$ não significativo; $* *$ = significativo a $1 \%$.

Fonte: Elaboração dos autores.

Com base nos resultados expostos no presente estudo, verifica-se que as cultivares de amendoim IAC 147, IAC Runner 886 (hábito de crescimento rasteiro), IAC 22 e IAC 8112 (hábito de crescimento ereto) apresentam fatores de resistência do tipo antibiose a $S$. bosquella, influenciando negativamente a sobrevivência de pelo menos um estágio de desenvolvimento do inseto. Resultados semelhantes foram obtidos por Pitta et al. (2010) avaliando os parâmetros biológicos de $A$. gemmatalis em oito cultivares de amendoinzeiro, sendo quatro de hábito de crescimento ereto e quatro de hábito rasteiro, que demonstraram que IAC 147 e IAC Runner 886 afetaram o desenvolvimento do inseto.

Assim, pesquisas futuras devem ser conduzidas a fim de se elucidar quais são as causas de resistência envolvidas nessas cultivares, quer sejam físicas, químicas ou morfológicas, a fim de que tais genes sejam incorporados em programas de melhoramento de plantas de amendoim visando ao controle dessa praga.

\section{Conclusões}

1. Nenhuma das cultivares de amendoim de hábito de crescimento rasteiro apresentaram resistência do tipo não preferência para alimentação.

2. Dentre as cultivares de hábito de crescimento ereto, IAC 5 e IAC 22 foram as menos atrativas e consumidas no teste de não preferência para alimentação com chance de escolha, e IAC 5 e IAC 
8112 foram as menos atrativas no teste sem chance de escolha.

3. As cultivares de amendoim de hábito de crescimento rasteiro IAC 147 e IAC Runner 886 afetaram a sobrevivência larval de $S$. bosquella, apresentando resistência do tipo antibiose.

4. Para as cultivares de hábito de crescimento ereto, IAC 22 e IAC 8112 afetaram a viabilidade larval, apresentando resistência do tipo antibiose.

5. As cultivares de hábito de crescimento rasteiro e ereto não influenciaram os parâmetros biológicos de peso de pupa, razão sexual e longevidade de $S$. bosquella.

\section{Agradecimentos}

Ao Dr. Ignácio José de Godoy, Pesquisador do Instituto Agronômico de Campinas, SP, pelo fornecimento das sementes das cultivares.

\section{Referências}

BOIÇA JÚNIOR, A. L.; FERRAREZZI, R.; RODRIGUES, N. E. L.; SOUZA, B. H. S.; BOTTEGA, D. B.; SILVA, A. G. Resistência de cultivares de amendoim de hábitos de crescimento ereto e rasteiro a Spodoptera cosmioides em laboratório.Agro@mbiente On-line, Boa Vista, v. 7, n. 1, p. 80-88, 2013.

BOIÇA JÚNIOR, A. L.; PITTA, R. M.; JESUS, F. G.; CAMPOS, A. P. Não-preferência para alimentação e para oviposição de genótipos de amendoim a Anticarsia gemmatalis Hübner (Lepidoptera: Noctuidae). Revista de Agricultura, Piracicaba, v. 83, n. 1, p. 66-74, 2008.

BOIÇA JÚNIOR, A. L.; RIBEIRO, Z. A.; CAMPOS, A. P.; CHAGAS FILHO, N. R. Técnica de criação e parâmetros biológicos de Stegasta bosquella em amendoim. Revista Caatinga, Mossoró, v. 24, n. 2, p. 192-196, 2011b.

BOIÇA JÚNIOR, A. L.; SILVA, A. G.; BOTTEGA, D. B.; RODRIGUES, N. E. L.; SOUZA, B. H. S.; PEIXOTO, M. L.; SOUZA, J. R. Resistência de plantas e o uso de produtos naturais como táticas de controle no manejo integrado de pragas. In: BUSOLI, A. C.; FRAGA, D. F.; SANTOS, L. C.; ALENCAR, J. R. C. C.; GRIGOLLI, J. F. J.; JANINI, J. C.; SOUZA, L. A.; VIANA, M. A.; FUNICHELLO, M. (Ed.). Tópicos em entomologia agrícola $-I V$. Jaboticabal: Gráfica e Editora Multipress, 2011a. p. 139-158.

BOIÇA JÚNIOR, A. L.; SOUZA, B. H. S.; BOTTEGA, D. B.; RODRIGUES, N. E. L.; PEIXOTO, M. L.; COSTA, E. N.; RIBEIRO, Z. A. Resistência de plantas e produtos naturais no controle de pragas em culturas agrícolas. In: BUSOLI, A. C.; GRIGOLLI, J. F. J.; SOUZA, L. A.; KUBOTA, M. M.; COSTA, E. N.; SANTOS, L. A. O.; CROSARIOL NETTO, J.; VIANA, M. A. (Ed.). Tópicos em entomologia agrícola - $V$. Jaboticabal: Gráfica Multipress, 2012. p. 151-171.

CALCAGNOLO, G.; LEITE, F. M.; GALLO, J. R. Efeitos da infestação do tripes nos folíolos do amendoinzeiro Enneothrips flavens (Enneothripiella) Moulton, 1941, no desenvolvimento das plantas, na qualidade da produção de uma cultura "das águas". O Biológico, São Paulo, v. 40, n. 8, p. 241-42, 1974.

CAMPOS, A. P.; BOIÇA JÚNIOR, A. L.; JESUS, F. G.; GODOY, I. J. Avaliação de cultivares de amendoim para resistência a Spodoptera frugiperda. Bragantia, Campinas, v. 70, n. 2, p. 349-355, 2011.

CAMPOS, A. P.; BOIÇA JÚNIOR, A. L.; RIBEIRO, Z. A. Não-preferência para oviposição e alimentação de Spodoptera frugiperda (J. E. Smith, 1797) (Lepidoptera: Noctuidae) por cultivares de amendoim. Arquivos do Instituto Biológico, São Paulo, v. 77, n. 2, p. 251-258, 2010.

COORDENADORIA DE ASSISTÊNCIA TÉCNICA INTEGRAL - CATI. Amendoim: produção em São Paulo e implicações no Mercosul. Campinas: CATI, 1997. 9 p. (Documento Técnico, 105).

COMPANHIA NACIONAL DE ABASTECIMENTO CONAB. Acompanhamento da safra brasileira: grãos, oitavo levantamento, maio/2012. Brasília: CONAB, 2012. 36 p.

Acompanhamento da safra brasileira: grãos, oitavo levantamento, maio/2014. Brasília: CONAB, 2014. $93 \mathrm{p}$.

GALLO, D.; NAKANO, O.; SILVEIRA NETO, S.; CARVALHO, R. P. L.; BATISTA, G. C.; BERTI FILHO, E.; PARRA, J. R. P.; ZUCCHI, R. A.; ALVES, S. B., VENDRAMIN, J. D.; MARCHINI, L. C.; LOPES, J. R. S.; OMOTO, C. Entomologia agrícola. Piracicaba: FEALQ, 2002. 920 p.

JANINI, J. C. Resistência de espécies silvestres de amendoim (Arachis spp.) ao ataque de Enneothripsflavens Moulton, 1941 (Thysanoptera, Thripidae) e Stegasta bosquella (Chambers, 1875) (Lepidoptera: Gelechiidae). 2009. Dissertação (Mestrado em Agronomia - Área de Concentração: Entomologia Agrícola) - Faculdade de 
Ciências Agrárias e Veterinárias, Universidade Estadual Paulista, Jaboticabal.

JANINI, J. C.; SOUZA, B. H. S.; BOIÇA JÚNIOR, A. L. Lagarta-do-pescoço-vermelho: Problema nosso. $A$ Granja, Rio Grande do Sul, v. 67, n. 746, p. 44-45, 2010.

LARA, F. M. Princípios de resistência de plantas a insetos. 2. ed. São Paulo: Ícone, 1991. 336 p.

LOURENÇÃO, A. L.; MORAES, A. R. A.; GODOY, I. J.; AMBROSANO, G. M. B. Efeito da infestação de Enneothrips flavens Moulton sobre o desenvolvimento de cultivares de amendoim. Bragantia, Campinas, v. 66, n. 4, p. 623-636, 2007.

MATUO, T. Danos da lagarta-do-pescoço-vermelho, Stegasta bosquella Chambers, 1875 (LepidopteraGelechiidae), em amendoinzeiro, Arachis hypogaea L. 1973. Tese (Doutorado em Agronomia Área de Concentração: Produção Vegetal) - Faculdade de Ciências Agrárias e Veterinárias, Universidade Estadual Paulista, Jaboticabal.
PITTA, R. M.; BOIÇA JÚNIOR, A. L.; JESUS, F. G.; TAGLIARI, S. R. A. Seleção de genótipos resistentes de amendoinzeiro a Anticarsia gemmatalis Hübner (Lepidoptera: Noctuidae) com base em análises multivariadas. Neotropical Entomology, Londrina, v. 39, n. 2, p. 260-265, 2010.

STALKER, H. T.; MOSS, J. P. Speciation, cytogenetics and utilization of Arachis species. Advances in Agronomy, San Diego, v. 41, p. 1-40, 1987.

TASSO JUNIOR, L. C.; MARQUES, M. O.; NOGUEIRA, G. A. A cultura do amendoim. Jaboticabal: FUNEP, 2004. 220 p. 